\title{
Mouse-killing and hyperemotionality in rats induced by three different kinds of experimental manipulations: A comparative study
}

\author{
HIROYUKI YOSHIMURA and SHOWA UEKI \\ Department of Pharmacology, Faculty of Pharmaceutical Sciences \\ Kyushu University, Fukuoka 812, Japan
}

\begin{abstract}
Male rats were subjected to one of three different kinds of manipulations: isolation housing, bilateral olfactory bulbectomy, and $\Delta^{9}$-tetrahydrocannabinol (THC) administration. All three treatments produced an increase in the tendency toward mouse-killing behavior and also affected the animal's emotionality. Each of these treatments, however, produced distinctive features in both the topography of killing response and hyperemotionality. Among the three models, isolation-induced killer rats exhibited the most well-organized killing response, while in both olfactory bulbectomy and THC-induced killer rats the killing response was characterized by inefficient, compulsive, and indiscriminate biting. The satiation of mouse-killing behavior did not occur in any of the three models. Isolation-induced killer rats were more reactive in startle response than were nonkiller rats, while THC-induced killer rats showed a higher reactivity to the presented wooden rod than did nonkiller rats. In olfactory bulbectomized rats, there was no significant difference in any behavioral items between killer and nonkiller rats. This evidence suggests that the mouse-killing behavior in rats is not a unitary phenomenon and that various physiological and psychological bases exist, depending upon the manipulation employed.
\end{abstract}

Mouse-killing behavior in domesticated rats is infrequent, and various experimental manipulations are necessary to induce this behavior: for example, isolation housing (e.g., Valzelli \& Garattini, 1972; Yoshimura \& Ueki, 1977); bilateral olfactory bulbectomy (e.g., Myer, 1964; Vergnes \& Karli, 1963); and $\Delta^{9}$-tetrahydrocannabinol (THC) administration (e.g., Ueki, Fujiwara, \& Ogawa, 1972; Yoshimura, Fujiwara, \& Ueki, 1974). Several investigators, however, have pointed out that the behavioral topography of the killing response in these experimentally induced killer rats differs from that of natural or spontaneous killer rats (Bernstein \& Moyer, 1970; Fujiwara \& Ueki, 1978; Miczek, 1976).

Mouse-killing behavior has been introduced into the pharmacological analysis of mode of action of psychotropic drugs (Malick, Sofia, \& Goldberg, 1969; Nurimoto, Ogawa, \& Ueki, 1974a; Sofia, 1969; Ueki, Nurimoto, \& Ogawa, 1972b) since Horovitz, Piala, High, Burke, and Leaf (1966) found that the behavior could be selectively suppressed by a certain class of drugs, such as antidepressants and stimulants. However, Malick (1976) has reported a quantitative difference in sensitivity to drugs between

Hiroyuki Yoshimura is now at the Department of Pharmacology, School of Medicine, Ehime University, Ehime 791-02, Japan. Requests for reprints should be sent to the first author. olfactory bulbectomized and spontaneous killer rats: For example, ED50 (50\% effective dose) of imipramine for the inhibition of the killing response was $9.9 \mathrm{mg} / \mathrm{kg}$ in spontaneous killer rats, while ED50 in bulbectomized killer rats was $25.8 \mathrm{mg} / \mathrm{kg}$. It appears, therefore, that the results obtained in pharmacological study are dependent upon the type of experimental manipulation employed.

Our previous reports also indicate that there are several different physiological bases in the mediation of killing response depending upon the kind of experimental manipulation: the isolation-induced killer rats exhibited higher acetylcholine levels in the diencephalon, while neither olfactory bulbectomized nor THC-induced killer rats showed any regional change specific to killing response (Yoshimura et al., 1974; Yoshimura, Gomita, \& Ueki, 1974; Yoshimura \& Ueki, 1977).

On the other hand, the manipulation that can induce a killing response is also known to alter rats' emotionality and general behavior: greater emotionality in isolated rats (e.g., Hatch, Wiberg, Balazs, \& Grice, 1963; Korn \& Moyer, 1968); hyperirritability and offensive nature in olfactory bulbectomized rats (e.g., Cain \& Paxinos, 1974; Kumadaki, Hitomi, \& Kumada, 1967; Malick, 1970); and behavioral abnormalities in THC-treated rats (see review by Paton \& Pertwee, 1973). Interestingly, both 
isolation and olfactory bulbectomy increase aggressive behavior (Bernstein \& Moyer, 1970), while acute injection of THC decreases various kinds of aggressive behavior in several animal species (Miczek, 1978). There is, however, little information concerning the relationship between mouse-killing behavior and changes in emotionality.

The present study was conducted to clarify three principal objectives. The first objective was to study comparatively the behavioral topography of the killing response induced by three different kinds of manipulations, as a determinant of satiety. The second objective was to learn the characteristics of the changes in the rat's emotional response induced by each experimental manipulation. Finally, we investigated whether or not the observed changes in emotional response were related to the manifestation of killing response. The animals were subjected to one of the following manipulations: prolonged isolation housing, bilateral olfactory bulbectomy, or THC administration. The emotionality in the rat was determined by evaluating the reactivity to external stimuli using a five-point rating scale.

\section{METHOD}

\section{Subjects}

All the animals employed were male Wistar rats supplied from Kyushu University Institute of Experimental Animals. Upon arrival, rats were housed communally for at least 10 days before each experimental manipulation and had free access to food and water. During the experimental periods, rats were housed individually in the isolation cages. Albino mice, each weighing between 20 and $30 \mathrm{~g}$, were used to test the mouse-killing behavior. The temperature in the vivarium was maintained at $22^{\circ} \pm 1{ }^{\circ} \mathrm{C}$, and a 12-h light-dark cycle (lights on at 7:00 a.m. and off at 7:00 p.m.) was kept constant.

\section{Apparatus}

The isolation cage was divided into five compartments, $18 \times$ $17 \times 17 \mathrm{~cm}$ each, and made of wire mesh. The compartments were separated by opaque plastic partitions. Under these conditions, rats were exposed to social stimuli such as squeaks and odors but did not have physical contact or visible stimuli.

\section{Procedure}

In the present experiment, spontaneous killer rats were eliminated from the subjects, and the incidence of such spontaneous killer rats was approximately $8 \%$ throughout this study.

Isolation housing. Forty rats, each weighing between 180 and $200 \mathrm{~g}$, were used. All the animals were housed individually for 30 days in the isolation cages and had free access to food and water. During this period, the mouse-killing behavior was tested at intervals of 5 days, while the emotionality was measured $1 \mathrm{~h}$ before and 30 days after isolation.

Bilateral olfactory bulbectomy. Forty rats, each weighing between 180 and $200 \mathrm{~g}$ at the time of surgery, were used. An olfactory bulbectomy was performed under pentobarbital anesthesia $(40 \mathrm{mg} / \mathrm{kg}$, ip). The olfactory bulbs were bilaterally removed by suction through two holes made in the skull just above the bulbs. The bulbectomized rats were housed individually in the isolation cages and had free access to food and water. The mouse-killing behavior was tested 3,7 , and 14 days after surgery. After the experiments, all bulbectomized animals were sacrificed and their brains were examined to ensure that the bulbs had been completely ablated.

THC administration. Thirty rats, each weighing between 120 ad $140 \mathrm{~g}$ at the time of drug administration, were used. The animals were housed individually and subjected to food deprivation for $24 \mathrm{~h}$ prior to THC administration. Natural THC, supplied by the Department of Pharmacognosy, Kyushu University, was suspended in a $1 \%$ aqueous Tween-80 solution and injected intraperitoneally in a dose of $6 \mathrm{mg} / \mathrm{kg}$. Mouse-killing behavior and emotionality were tested $30 \mathrm{~min}$ before and $1 \mathrm{~h}$ after THC administration.

Behavioral testing. Mouse-killing behavior was determined by introducing an albino mouse into the rat's home cage, and the rat that killed the mouse within 5 min was judged to be a killer; those that failed to do so were termed nonkillers.

Satiety of killing response was evaluated by determining the number of killed mice in successive introductions of a mouse into a rat's home cage without removing the killed mice. The test was conducted for $5 \mathrm{~min}$, and the prey were introduced one by one after confirmation that the previous mouse had been killed. An equal number of killer rats $(n=5)$ from each treatment group were randomly selected and employed for this purpose.

The emotionality was evaluated on the basis of the response to the following stimuli: (1) a wooden rod presented in front of the snout (attack response), (2) capture and handling by experimenter (struggle response), (3) pinching the tail with a forceps (startle response), and (4) vocalization during capture and handling. These responses on each item were graded by means of a fivepoint rating scale: score $0=$ no reaction, $1=$ slight, $2=$ moderate, $3=$ marked, and $4=$ extreme response. Simple blind observations were performed. The details of the scoring procedure were as follows. In the case of the attack biting response, score 0 indicated that the rat was indifferent to the rod with no movement toward it, 1 indicated that the rat approached and explored the rod, 2 indicated that the rat licked and slightly bit the rod, 3 indicated that the rat attacked of fensively with closed eyes and bit the rod immediately, and 4 indicated that the rat crunched the rod noisily and exhibited a tendency to continue biting the rod when the experimenter withdrew it. In scoring the struggle response, attention was paid to the tonicity of the rat's abdominal muscle during capture and handling, in addition to observing the difficulty in capture. Score 0 indicated no resistance to capture and no special muscle tonus (as with an anesthetized animal), 1 indicated that the rat was easily captured and could be held quietly, 2 indicated that the rat was easily captured but showed a slight muscle tonus with a weak squeak, 3 indicated that the rat was captured with difficulty and showed strong muscle tonus with frequent squeaks, and 4 indicated that the rat tried to bite the experimenter's hand, preventing the experimenter from continuing to hold the animal. The startle response was evaluated by the following points: score 0 indicated that the rat was indifferent and did not turn to the forceps, 1 indicated that the rat turned back and sniffed the forceps slightly, 2 indicated that the rat sniffed with a weak squeak and sometimes tried to escape from the pinching, 3 indicated that the rat bit the forceps immediately and struggled to escape, and 4 indicated that the rat showed vigorous flight reaction with a shrill squeak and violent biting and the experimenter usually could not keep pinching the tail. The vocalization scoring was based on the degree of both frequency and tone: score 0 indicated no vocalization, 1 indicated no more than two or three slight and weak squeaks, 2 indicated frequent but weak squeaks, 3 indicated shrill squeaks, and 4 indicated frequent shrill squeaks. On the testing day, the rats were first tested for the killing response and then were measured in sequence for attack biting, struggle response, vocalization, and startle response. An equal number of animals (killer rats $=8$, and nonkiller rats $=8$ ) from each treatment group were randomly selected and their emotionality was measured. 


\section{Statistical Analysis}

The statistical evaluation of the satiety test of killing response was performed by means of analysis of variance, and differences among the three models were analyzed using the Tukey test. The score of each emotional response graded on a five-point rating scale was also evaluated by analysis of variance, and further analysis of multiple comparisons between killer and nonkiller or among the models was performed using the Tukey test. Differences between pre- and posttreatment levels were analyzed by means of a nonparametric sign test (Siegel, 1956).

\section{RESULTS}

\section{Incidence of Mouse-Killing Behavior}

Table 1 shows the proportion and percentage of killer rats. In both isolation(Iso)-induced and olfactory bulbectomized (OB) killer rats, once killing behavior had developed, it was constant and did not disappear under repeated measurements. The killing response in THC-treated rats lasted for at least $3 \mathrm{~h}$ and disappeared $24 \mathrm{~h}$ after injection of the drug.

\section{Behavioral Topography and Satiety of Killing Response}

As shown in Table 2, there is a significant difference in the number of killed mice among the three groups of killer rats $[F(2,12)=84.25, p<.001]$. Isoinduced killer rats killed mice consecutively and almost ceaselessly by the most effective means-after exploratory sniffing of the mouse for a few brief moments, the rat suddenly attacked and bit in the cervical region during the initial attack. The number of killed mice in the Iso group was significantly higher than in the OB or THC group $(p<.01)$. Although OB-induced killer rats attacked immediately after introduction of the mouse, their attack bitings were so violent that they sometimes failed

Table 1

Incidence of Mouse-Killing Behavior

\begin{tabular}{|c|c|c|c|}
\hline Manipulators & $\begin{array}{c}\text { Number } \\
\text { Tested }\end{array}$ & $\begin{array}{l}\text { Number of } \\
\text { Killers }\end{array}$ & $\begin{array}{c}\% \\
\text { Killers }\end{array}$ \\
\hline Isolation Housing* & 40 & 17 & 43 \\
\hline Olfactory Bulbectomy** & 40 & 25 & 63 \\
\hline THC Administration $\dagger$ & 30 & 18 & 60 \\
\hline
\end{tabular}

*30 days of isolation housing. $\quad * * 14$ days after surgery.

$\dagger 1 \mathrm{~h}$ after injection of $\mathrm{THC}(6 \mathrm{mg} / \mathrm{kg}$, ip).

Table 2

Number of Killed Mice in Successive Introduction of the Mouse

\begin{tabular}{lcc}
$\begin{array}{c}\text { Types of } \\
\text { Killer Rat }\end{array}$ & $\begin{array}{c}\text { Number } \\
\text { Tested }\end{array}$ & $\begin{array}{c}\text { Number of } \\
\text { Mice Killed* }\end{array}$ \\
\hline Socially Isolated & 5 & $12.8 \pm .5$ \\
Olfactory Bulbectomized & 5 & $9.6 \pm .7$ \\
THC Administered & 5 & $1.8 \pm .3$ \\
\hline
\end{tabular}

*Each value shows mean $\pm S E$. to catch and hold the mice with their paws. The killing response had a compulsive, disinhibited quality, and, in many cases, the killed mice were covered with blood from head to tail. THC-induced killer rats killed only one or two mice during the 5-min test period-significantly fewer than the Iso and $O B$ groups ( $p<.01)$. At the first introduction of a mouse into the cage, the THC-treated animal retreated to a corner of the cage, cowered there with startled squeals, and then suddenly attacked the mouse. The killing response was not efficient enough to inflict lethal damage on the mice: The rats bit not only in the cervical region, but also on the head or on the ventral side, and did not release the dead mouse but continued to bite even when the next mouse was introduced into the cage.

\section{Emotionality}

The mean score of each behavioral response obtained before and after the three experimental manipulations is shown in Figures 1-4 for both the killer (A) and the nonkiller (B) rats. In these experiments, the pretreatment level for each item did not differ between killer and nonkiller rats or among the three experimental treatments. The rats employed in the present study were quite tame and easily handled by the experimenter when they had been housed communally without experimental manipulations. The mean score of normal rats $(n=8)$ was as follows: $1.3 \pm .2$ for attack response, $1.2 \pm .1$ for struggle response, $1.1 \pm .1$ for startle response, and $.2 \pm .2$ for vocalization.

Attack response. All experimental manipulations affected significantly the attack response of the animal as compared with the corresponding pretreatment levels of both killer and nonkiller rats (Figure 1). Analysis of variance revealed a significant difference in posttreatment level between killer and nonkiller rats $[\mathrm{F}(1,45)=18.85, \mathrm{p}<.001]$. The multiple comparisons with the Tukey test indicated that killer rats in the THC group were more reactive than nonkiller rats $(p<.01)$, while in the Iso or OB groups no significant difference was demonstrated. On the other hand, there was no significant difference in the ability to induce the high reactivity to the rod among the three experimental manipulations $[\mathrm{F}(2,45)$ $=3.20$, n.s.].

Struggle response. Effects of experimental manipulations on the struggle response are shown in Figure 2. In comparisons of posttreatment levels, the score of killer rats did not differ from that of nonkiller rats $[F(1,45)=.04$, n.s.], while significant difference was found among the three treatments $[F(2,45)=24.52, p<.001]$. Further analysis of multiple comparisons revealed the following relationships. The most effective treatment among the three groups was $\mathrm{OB}(\mathrm{OB}$ vs. Iso: $\mathrm{p}<.01 ; \mathrm{OB}$ vs. 


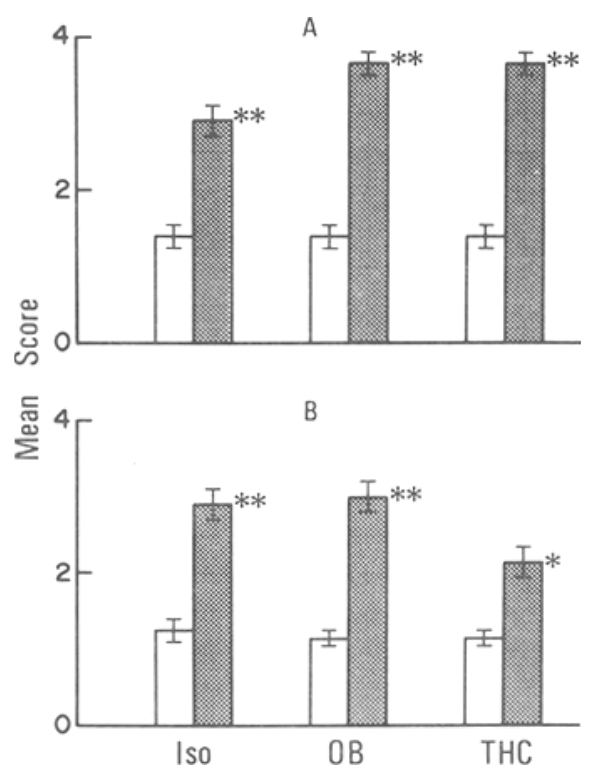

Figure 1. Mean score of attack response. Note abbreviations: Iso = isolation housing; $\mathrm{OB}=$ olfactory bulbectomy; THC $=\Delta^{9}$. tetrahydrocannabinol; $\mathbf{A}=$ killer rats; $B=$ nonkiller rats. The white column shows pretreatment level, and the stippled one shows posttreatment level $\left({ }^{*} p<.05 ;{ }^{* *} p<.01\right.$; as compared with the corresponding pretreatment level, sign-test).

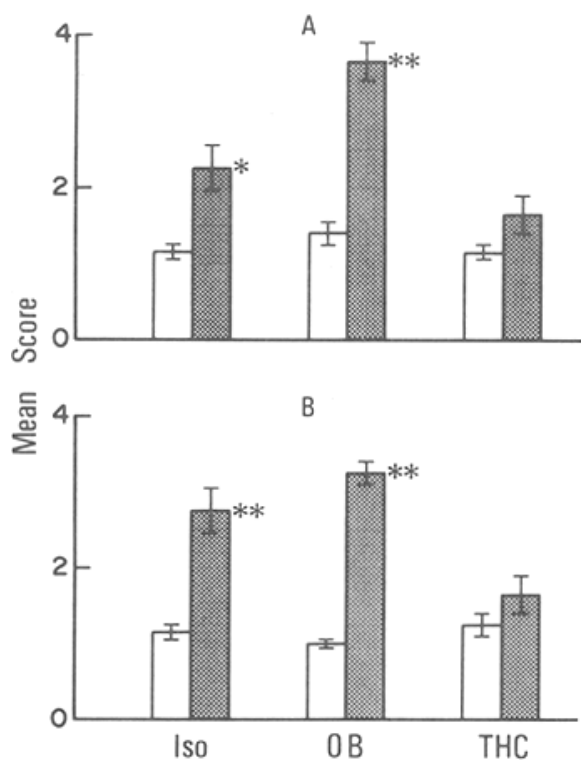

Figure 2. Mean score of struggle response. For abbreviations, see legend to Figure 1.

THC: $\mathrm{p}<.01$ ], and the next was Iso (Iso vs. THC: $\mathrm{p}<.01)$.

Startle response. Comparing the pretreatment level with the posttreatment level, a significant difference was demonstrated in the $\mathrm{OB}$ group and killer rats of the Iso group (Figure 3). There was a significant difference in the ability to induce high reactivity among the three treatments $[\mathrm{F}(2,45)=80.16, \mathrm{p}<$ $.001]$. Results of multiple comparisons indicated the following relationships. In killer rats, the highest score was obtained following olfactory bulbectomy (OB vs. Iso: $p<.01$; OB vs. THC: $p<.01$ ), and the next was Iso (Iso vs. THC: $p<.01$ ). Nonkiller rats with olfactory bulbectomy also showed the highest score among the three nonkiller groups, with no significant difference between Iso- and THC-treated nonkiller rats, while no significant difference was demonstrated between killer and nonkiller rats $[F(1,45)=2.41$, n.s. $]$.

Vocalization. All treatments affected the vocalization of the animal as compared with the corresponding pretreatment levels, independently of manifestation of mouse-killing behavior (Figure 4). There were significant differences among the three treatment groups $[F(2,45)=5.91, p<.01]$, while none was found between killer and nonkiller rats $[F(1,45)=$ .91 , n.s.]. As a result of multiple comparisons, the following relationships were demonstrated: The THC group in both killer and nonkiller rats showed the highest score (THC vs. Iso: $p<.01$; THC vs. OB: $\mathrm{p}<.01$ ), with no significant difference between Iso and $O B$ groups.

\section{DISCUSSION}

The fact that all three experimental manipulations elicited the mouse-killing behavior in nonkiller rats is in general accord with previous results (Ueki et al., 1972; Vergnes \& Karli, 1963). The topography of killing response, however, differed markedly among the three models. The killing response that is pro-

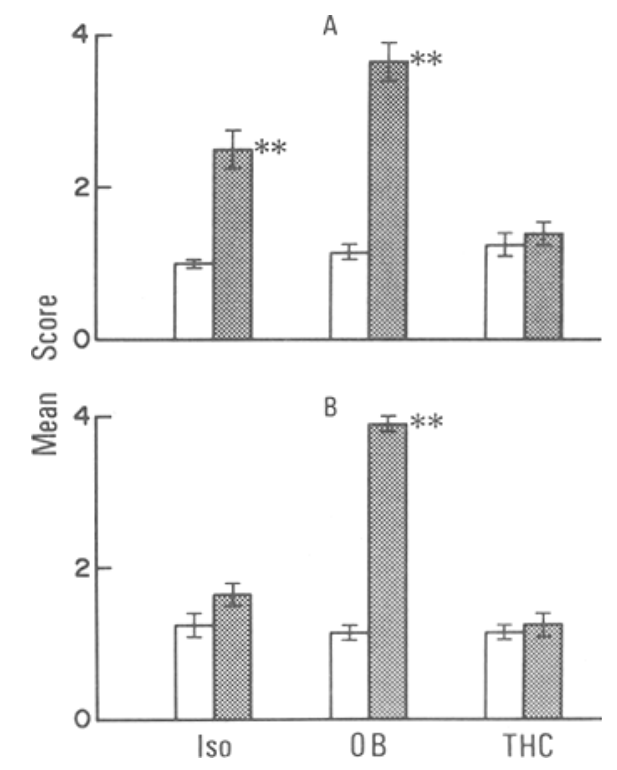

Figure 3. Mean score of startle response. For abbreviations, see legend to Figure 1. 


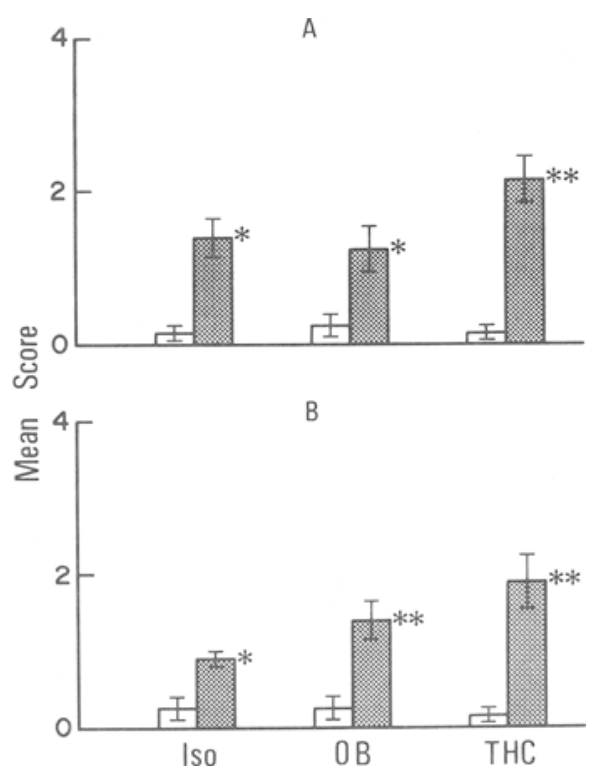

Figure 4. Mean score of vocalization. For abbreviations, see legend to Figure 1.

duced by prolonged isolation housing had a quality similar to that observed in natural or spontaneous killer rats: quiet, quick, and efficient attack-biting to the cervical region with little or no affective display (Bandler \& Chi, 1972; Bernstein \& Moyer, 1970; Karli, 1956). On the contrary, killer rats with olfactory bulb ablations did not exhibit such a wellorganized killing response. As repeatedly confirmed by several investigators (Bandler \& Chi, 1972; Bernstein \& Moyer, 1970; Cain \& Paxinos, 1974; Karli, 1956), it appears that their killing response includes irritable aggressive components. It is noteworthy that the killing response induced by THC was quite different from the others. The attack-biting was poorly directed for killing; that is, the biting extended over the mouse's entire body. In addition, THC-induced killer rats continued to bite the mouse after its death, despite the fact that they had exhibited a frightened posture toward the mouse before attacking.

Kulkarni (1968) has reported that half of the spontaneous killer rats discontinued their killing response when mice were introduced into the cage every $15 \mathrm{~min}$ over 7 trials/day. He explained this phenomenon as "satiation," such as that occurring when a hungry rat satiates after obtaining a sufficient amount of food. In the present experiment, however, the satiation of mouse-killing behavior did not occur in any of the three models. Although THC-induced killer rats killed only one or two mice, this was probably due to their tenacity toward the killed mouse rather than to satiation. In fact, when the killed mouse was removed from the cage, the THC-induced killer rats attacked and killed the next mouse. Therefore, it is not likely that Kulkarni's finding is common to all mouse-killing behavior. In connection with this, it has been indicated that repeated performance of killing response results in increased reliability and the short latency to kill the mouse (Karli, 1956; Myer, 1964; Myer \& White, 1965).

Although all three treatments affect the animal's emotionality, the three models can be distinguished by their patterns of reaction to external stimuli. Following prolonged isolation housing, the score on the three items (attack, struggle, and vocalization) increased significantly regardless of killing response. However, the only specific change in the emotionality of killer rats was observed in the startle response. Previous research has indicated that isolation housing leads to heightened emotionality in rats (Bernstein \& Moyer, 1970; Hatch et al., 1963; Korn $\&$ Moyer, 1968) but has not shown whether the observed emotionality in a variety of test situations is a specific change in the manifestation of mousekilling behavior. On the other hand, rats with bilateral olfactory bulbectomy exhibited high reactivity in all emotional responses employed in this study, and their response to inanimate objects or the experimenter was highly offensive in nature. These results are consistent with previous reports that olfactory bulbectomized rats showed increased irritability and aggressiveness (Cain, 1974; Cain \& Paxinos, 1974; Kumadaki et al., 1967; Malick, 1970; Nurimoto et al., 1974a, 1974b; Ueki et al., 1972a, 1972b). However, no significant difference was demonstrated between killer and nonkiller rats. Therefore, it appears that these emotional changes do not relate to the killing response itself, induced by olfactory bulbectomy. Bernstein and Moyer (1970) reported that biting the gloved hand is the only type of aggressive behavior significantly affected by olfactory bulbectomy, and they also found a significant correlation between mouse-killing and the number of bites on the gloved hand. In their experiments, however, olfactory bulb lesions did not significantly increase the mouse-killing tendency of the animals. Changes in emotionality induced by the administration of THC, as well as its killing response, showed a distinctive feature: Both struggle and startle response were not affected, but most of the THC-treated animals vocalized frequently during the measurement of emotionality. The vocalization by THC has been noticed (Henriksson \& Jarbe, 1971; Jarbe \& Henriksson, 1973), but its physiological significance is still unclear. Jarbe and Henriksson found that THC-induced vocalization is inhibited by tranquilizers and suggested that vocalization is primarily a sign of distress rather than a pain reaction. It is clear from the present experiments that the frequent vocalizations do not relate directly to mouse-killing behav- 
ior. Rather, a characteristic of THC-induced killer rats seems to be their higher reactivity to the presented wooden rod.

The present findings that different kinds of manipulations have different effects on both the topography of killing response and the emotional response to external stimuli suggest that the behavior that is referred to generically as "mouse-killing behavior" includes, in fact, several physiological and psychological bases depending upon the experimental manipulation employed. Although Moyer (1968) classified mouse-killing behavior as predatory aggression, it appears that the manifestation of killing behavior is brought about by a more complicated motivational state than predation, apart from whether predation can be considered "aggression." Myer and Baenninger (1966) proposed that the inner state of a killer rat can be explained by attack and arousal mechanisms: When the mouse is introduced into a rat's home cage, the rat is aroused by a variety of emotions such as curiosity, fear, and sexual motivation, and when the increased arousal level reaches the threshold of the attack mechanism, the animal attacks and kills the mouse. This working hypothesis seems to be applicable to the experimentally induced mouse-killing behavior. The distinct features in killing response and emotionality among the three models may be accounted for by assuming that each treatment acts differentially on the rat's inner state, tending to increase the arousal level, and that this reflects on the different behavioral topography of killing behavior. Therefore, it is conceivable that mouse-killing behavior in rats is not a unitary phenomenon.

\section{REFERENCES}

Bandler, R. J., JR., \& Chi, C. C. Effects of olfactory bulb removal on aggression: A reevaluation. Physiology \& Behavior, 1972, 8, 207-211.

Bernstein, H., \& Moyer, K. E. Aggressive behavior in the rat: Effects of isolation and olfactory bulb lesions. Brain Research, 1970, 20, 75-84.

CAIN, D. P. Olfactory bulbectomy: Neural structures involved in irritability and aggression in the male rat. Journal of Comparative and Physiological Psychology, 1974, 86, 213-220.

Cain, D. P., \& Paxinos, G. Olfactory bulbectomy and mucosal damage: Effects on copulation, irritability, and interspecific aggression in male rats. Journal of Comparative and Physiological Psychology, 1974, 86, 202-212.

Fujiwara, M., \& UEKI, S. Muricide induced by single injection of $\Delta^{9}$-tetrahydrocannabinol. Physiology \& Behavior, 1978, 21, 581-585.

Hatch, A. M., Wiberg, G. S., Balazs, T., \& Grice, H. C. Long term isolation stress in rats. Science, 1963, 142, 507.

Henriksson, B. G., \& Jarbe, J. J. Cannabis-induced vocalization in the rat. Journal of Pharmacy and Pharmacology, 1971, $23,457-458$.

Horovitz, Z. P., Piala, J. J., High, J. P., Burke, L. C., \& LEAF, R. C. Effects of drugs on the mouse-killing test and its relationship to amygdaloid function. International Journal of Neuropharmacology, 1966, 5, 405-411.

Jarbe, T., \& Henriksson, B. G. Vocalization: A characteristic cannabis-induced behavior in the rat? Physiological Psychology, 1973, 1, 351-353.

KARLI, P. The Norway rat's killing response to the white mouse: An experimental analysis. Behaviour, 1956, 10, 81-103.

KORN, J. H., \& MOYER, K. E. Behavioral effects of isolation in the rat: The role of sex and time of isolation. Journal of Genetic Psychology, 1968, 113, 263-273.

KulKarNi, A. S. Satiation of instinctive mouse killing by rats. Psychological Record, 1968, 18, 385-388.

Kumadaki, N., Нiтomi, M., \& Kumada, S. Effect of psychotherapeutic drugs on hyperemotionality of rats in which the olfactory bulb was removed. Japanese Journal of Pharmacology, 1967, 17, 659-667.

MALICK, J. B. A behavioral comparison of three lesion-induced models of aggression in the rat. Physiology \& Behavior, 1970, 5, 679-681.

Malick, J. B. Pharmacological antagonism of mouse-killing behavior in the olfactory bulb lesion-induced killer rat. Aggressive Behavior, 1976, 2, 123-130.

Malick, J. B., Sofia, R. D., \& Goldberg, M. E. A comparative study of the effects of selected psychoactive agents upon three lesion-induced models of aggression in the rat. Archives of International Pharmacodynamics and Therapy, 1969, 181, 459-465.

Micze K, K. A. Mouse-killing and motor activity: Effects of chronic $\Delta^{9}$-tetrahydrocannabinol and pilocarpine. Psychopharmacology, 1976, 47, 59-64.

MiCZEK, K. A. $\Delta^{9}$-tetrahydrocannabinol: Antiaggressive effects in mice, rats and squirrel monkeys. Science, 1978, 199, 1459-1461.

MOYER, K. E. Kinds of aggression and their physiological basis. Communications in Behavioral Biology, 1968, 2, 65-87.

MYER, J. S. Stimulus control of mouse-killing rats. Journal of Comparative and Physiological Psychology, 1964, 58, 112-117.

Myer, J. S., \& Baenninger, R. Some effects of stress and punishment on mouse-killing by rats. Journal of Comparative and Physiological Psychology, 1966, 62, 292-297.

Myer, J. S., \& White, R. T. Aggressive motivation in the rat. Animal Behaviour, 1965, 13, 430-433.

Nurimoto, S., Ogawa, N., \& UEKI, S. Effects of psychotropic drugs on hyperemotionality of rats with bilateral ablations of the olfactory bulbs and olfactory tubercles. Japanese Journal of Pharmacology, 1974, 24, 185-193. (a)

Nurimoto, S., Ogawa, N., \& UeKI, S. Hyperemotionality induced by lesions in the olfactory system of the rat. Japanese Journal of Pharmacology, 1974, 24, 175-184. (b)

Paton, W. D. M., \& Pertwee, R. G. The pharmacology of cannabis in animals. In R. Mechoulam (Ed.), Marijuana. New York: Academic Press, 1973.

SiEgeL, S. Nonparametric statistics for the behavioral sciences. New York: McGraw-Hill, 1956.

SofiA, R. D. Structural relationship and potency of agents which selectively block mouse killing (muricide) behavior in rats. Life Science, 1969, 8, 1201-1210.

Ueki, S., Fujiwara, M., \& Ogawa, N. Mouse-killing behavior (muricide) induced by $\Delta^{9}$-tetrahydrocannabinol in the rat. Physiology \& Behavior, 1972, 9, 585-587.

Ueki, S., Nurimoto, S., \& Ogawa, N. Characteristics in emotional behavior of the rat with bilateral olfactory bulb ablations. Folia Psychiatrica et Neurologica Japonica, 1972, 26, 227-237. (a)

Ueкi, S., Nurimoto, S., \& Ogawa, N. Effects of psychotropic drugs on emotional behavior in rats with limbic lesions, with special reference to olfactory bulb ablations. Folia Psychiatrica et Neurologica Japonica, 1972, 26, 245-255. (b)

Valzelli, L., \& Garattini, S. Biochemical and behavioral changes induced by isolation in rats. Neuropharmacology, 1972, 11, 17-22. 
Vergnes, M., \& Karli, P. Déclenchement du comportement d'agression interspécifique rat-souris par ablation bilatérale des bulbes olfactifs. Comptes Rendus des Séances de Société de Biologie, 1963, 157, 1061-1063.

Yoshimura, H., Fujiwara, M., \& Ueki, S. Biochemical correlates in mouse-killing behavior of the rat: Brain acetylcholine and acetylcholinesterase after administration of $\Delta^{9}$-tetrahydrocannabinol. Brain Research, 1974, 81, 567-570.

Yoshimura, H., Gomita, Y., \& UeкI, S. Changes in acetylcholine content in rat brain after bilateral olfactory bulbectomy in relation to mouse-killing behavior. Pharmacology, Biochemistry \& Behavior, 1974, 2, 703-705.

YoshimurA, H., \& UEKI, S. Biochemical correlates in mousekilling behavior of the rat: Prolonged isolation and brain cholinergic function. Pharmacology, Biochemistry \& Behavior, 1977, 6, 193-196.

(Manuscript received January 29, 1981; revision accepted for publication June 2, 1981.) 